\title{
Avoiding the Non-Detection Zone of Passive Loss-of-Mains (Islanding) Relays for Synchronous Generation by using Low Bandwidth Control Loops and Controlled Reactive Power Mismatches
}

\author{
Andrew J. Roscoe, Graeme M. Burt and Chris G. Bright
}

\begin{abstract}
Generation connected to electrical distribution systems requires reliable and timely detection of loss-of-mains (islanding). Passive loss-of-mains detection relays typically use measurements of parameters such as frequency, phase, and the magnitudes of voltage and current. If a part of the power network becomes islanded and there is a very close match between generation and demand of both active and reactive power, there is a risk that the relay will not be able to detect the loss-of-mains (LOM) event quickly, or perhaps at all. This is the "non-detection zone" or NDZ. This paper proposes a combination of 2 generator control techniques which allow the NDZ to be avoided even when the generator has significant inertia. Firstly, the natural instability (when islanded) of a grid-connected control scheme consisting of integral and droop controls is recognized and exploited. Secondly, a simple strategy is added which makes occasional small, steady-state adjustments to the reactive power output of the generator. The scheme has been tested in the laboratory and shows that the 2 second detection time required by IEEE 1547 can be achieved, even when an exact match of active power generation and demand is initially configured, and the generator has a significant inertia.
\end{abstract}

Index Terms-- AC generators, AC generator excitation, Power generation, Power systems, Power system control, Power system protection, Power system security, Protective relaying, Reactive power, islanding, loss-of-mains.

\section{NOMENCLATURE}

$\tau_{D P} \quad$ Time constant for active power droop filter (s)

$\tau_{D Q} \quad$ Time constant for reactive power droop filter (s)

$D_{F} \quad$ Frequency droop slope, typically $0.05(5 \%)$

$D_{V} \quad$ Voltage droop slope, typically $0.1(10 \%)$

$f_{M} \quad$ Measured frequency (pu)

This work was supported in part by Rolls-Royce PLC.

A. J. Roscoe is with University of Strathclyde, Glasgow, UK (e-mail: Andrew.J.Roscoe.@strath.ac.uk).

G. M. Burt is with University of Strathclyde, Glasgow, UK (e-mail: Graeme.Burt.@strath.ac.uk).

C. G. Bright is with the Strategic Research Centre, Rolls-Royce, UK, (email: chris.bright@rolls-royce.com).

This is a postprint of a paper published in IEEE Transactions on Smart Grids [http://dx.doi.org/ 10.1109/TSG.2013.2279016] and is subject to IEEE copyright. $f_{0} \quad$ Nominal frequency $(\mathrm{pu})$

$H \quad$ DG per-unit inertia (s)

$K_{i P} \quad$ Integral control gain for active power, typically 1

$K_{i Q} \quad$ Integral control gain for reactive power, typically 1

$L_{P}(s) \quad$ Local load active power response to frequency

$L_{Q} \quad$ Local load reactive power response to voltage

$M_{F}(s) \quad$ Low-pass filter to model frequency measurement time

$M_{V}(s) \quad$ Low-pass filter to model voltage measurement time

$M_{P}(s) \quad$ Low-pass filter to model active power measurement time

$M_{Q}(s) \quad$ Low-pass filter to model reactive power measurement

$P_{D} \quad$ Active power target adjustment according to droop

$P_{G e n} \quad$ Active power from distributed generator (DG) (pu)

$P_{\text {Loads }} \quad$ Active power supplied to local loads (pu)

$P_{\text {Net }} \quad$ Active power supplied by the utility network (pu)

$P_{\text {Set }} \quad$ Active power setpoint (pu)

$P_{t} \quad$ Lower threshold of $P_{\text {Net }}$ to avoid the NDZ

$P^{*} \quad$ Active power target $=($ filtered $)\left(P_{\text {Set }}+P_{D}\right)(\mathrm{pu})$

$P_{\text {Trapped }}$ Active power back-fed to trapped loads during LOM

$\tau_{Q} \quad$ Time constant to model field response (s)

$Q_{D} \quad$ Reactive power target adjustment according to droop

$Q_{\text {Gen }} \quad$ Reactive power from distributed generator (DG) (pu)

$Q_{\text {Loads }} \quad$ Reactive power supplied to local loads (pu)

$Q_{\text {Net }} \quad$ Reactive power supplied by the utility network (pu)

$Q_{\text {Set }} \quad$ Reactive power setpoint (pu), typically 0

$Q_{t} \quad$ Lower threshold of $Q_{\text {Net }}$ required to avoid the NDZ

$Q^{*} \quad$ Reactive power target $=($ filtered $)\left(Q_{S e t}+Q_{D}\right)(\mathrm{pu})$

$Q_{\text {Trapped }}$ Reactive power back-fed to trapped loads during LOM

$V_{M} \quad$ Measured voltage (pu)

$V_{0} \quad$ Nominal voltage (pu), normally 1

$X \quad$ DG per-unit reactance

\section{INTRODUCTION}

$\mathrm{W}$ HEN distributed generation (DG) is installed within an electrical power network, a loss-of-mains (LOM) (also known as "islanding") event can occur if the connection to the utility system as a whole is lost, for example if an interconnection is severed due to a fault or the opening of switchgear. The latter can be an accidental or deliberate event. Such an event can lead to the sudden formation of an islanded
$\tau_{P} \quad$ Time constant to model throttle response (s) 
power system, energized by the distributed generator. Timely detection of this condition is important for two reasons. Firstly, the distributed generator presents a risk of electric shock by energising parts of the utility system that might otherwise be considered dead. Secondly, an islanded generator presents a risk of an out-of-phase re-closure when the interconnection to the utility is restored.

Where the DG installation is inverter-connected, many active techniques for LOM detection such as [1-4] have been proposed. These require the injection of higher-order harmonic currents or modulated waveforms, and can detect the LOM condition because it manifests as a lowering of the fault level (increase in the network impedance) or via the detection of correlated voltage fluctuations. These methods have the following disadvantages: degrading local power quality, mutual interference between multiple devices (especially using different injection methods), and the requirement for injection hardware.

Other authors have proposed the detection of LOM by measuring the frequency at the DG and comparing it with the frequency measured at one or more distant points on the utility system [5], aided by GPS time stamped phase measurements $[6,7]$ at those points. Such methods are based on a simple principle, and desirable but require the expense of regular low-latency telecommunications and also local back-up protection should telecommunications fail.

This paper restricts its attention to the detection of LOM using local passive detection methods, such as commonly made with a ROCOF or vector-shift relay. Such relays detect the change in local power system frequency which a LOM event will usually cause. References [8,9] have compared ROCOF relays with vector shift and have found in favour of the ROCOF relay. The ROCOF relays usually contain an under-voltage element which discriminates between loss-of mains and other faults, and this discrimination can be improved by measuring voltage balance also, because islanding causes all three phases to suffer similar changes in voltage [9] [10,11]. New types of passive relay based upon estimates of phase change are proposed in $[8,12-15]$. These offer equal or better sensitivity than that of a ROCOF relay, but better discrimination against noise, switching events and faults other than LOM. Other proposed passive detection methods focus purely on the balance of reactive power [16].

The problem faced by all passive LOM detection relays which do not use telecommunications is that there is a finite risk of non-detection. This can occur when there is an almost exact match between the active and reactive DG power generation and the active and reactive power demand within the local power system, prior to the islanding. In this case, the local frequency and voltage level may remain steady and within statutory limits such that the accidental island is not detected within the required time ( 2 seconds by IEEE 1547 [17]) or possibly not at all. The boundary of active (P) and reactive $(\mathrm{Q})$ power match which defines the region of such non-detection is called the non-detection zone (NDZ) of the relay [18-20]. The NDZ for inverter-connected generation is dominated by the inverter interface control software and the PLL dynamics. In conventional inverters, there is no deliberate emulation of inertia, and so the behaviour of the inverter upon accidental islanding is determined by the high-bandwidth dynamics of the PLL coupled to the cascaded inner currentcontrol and outer $\mathrm{P} / \mathrm{Q}$ control loops. Usually, this control system is highly unstable when islanded, particularly in frequency, and so the NDZ of inverter-fed systems can be very small. For synchronous generator types, which are the primary focus of this paper, the inertia is fixed by the rotating plant and places constraints on the minimum size of the NDZ.

However, several previous studies have shown that for synchronous generators, the NDZ can cover situations where the $\mathrm{P}$ or $\mathrm{Q}$ match is as small as $2.5 \%$ of the DG rating, prior to the LOM event $[8,9,11]$. Nevertheless, the varying size of the NDZ reported by previous works such as $[8-15,18-20]$ highlights how the size of the NDZ is heavily influenced by the architecture of the control loops determining the DG real and reactive power export; i.e. the prime mover governor/throttle and the automatic voltage regulator (AVR) and field. The control strategy for both active and reactive power must be understood in order to define the NDZ. For synchronous generation, some authors $[21,22]$ have presented novel gridconnected DG control loop strategies which insert bandpass filter elements to make the control system deliberately unstable when islanded, in order to minimize the NDZ. These have the disadvantage of disrupting the action of conventional droop controllers and limiting the ability of the DG units to provide network support. This paper presents an alternative, simpler DG control scheme for use when the DG is connected to the utility. This allows conventional droop controls to be retained and thus allows the DG unit to contribute to network frequency and voltage support functions.

Furthermore, [23] presented a method for deliberately steering DG active power export away from a value which would cause a balance of active power within a local power system. This would affect the power generated and possibly the revenue earned by the DG. In contrast, this paper proposes a new method which makes only small adjustments to the DG reactive power output. An automatic control algorithm regularly checks for an almost exact active and reactive power balance between local DG and loads. If such a match exists, the control system changes the DG reactive power output slightly, in order to deliberately avoid the NDZ. This avoids changes to the active power scheduling which might diminish the revenue from a DG unit. Also, this technique allows the DG active power to be deliberately matched to the local active demand power. This can be desirable while the DG is connected to the utility, particularly when the stability of the utility network is in question and there is a perception that an islanding event may occur (due to protection action or deliberate disconnection). This is because it reduces the risk of gross frequency disturbances within the local network, because its active power is already locally balanced. It can also be shown that this technique is relatively robust in the presence of extra unknown "trapped" load.

This is a postprint of a paper published in IEEE Transactions on Smart Grids [http://dx.doi.org/ 10.1109/TSG.2013.2279016] and is subject to IEEE copyright. 


\section{GRID-CONNECTED CONTROL TO MINIMISE THE NDZ}

During the course of this work, different control strategies for synchronous generators up to $80 \mathrm{kVA}$ have been tested in the laboratory. Generally, there is a direct trade-off between the stability of the control scheme (its suitability to be used in during islanded operation) and its suitability for use when connected to the utility where minimization of the NDZ is most important. Thus, although control schemes with frequency and voltage control are stable in islanded operation, they give the largest NDZs. Conversely, control schemes such as those of $[21,22]$ are unable to sustain stable islanded performance but help to minimize the NDZ. Thus, control for a DG unit should switch between different modes depending upon whether the DG is islanded mode (single or multiple generators sharing) or connected to the utility. Suitable schemes for the islanded mode are outside the scope of this paper, but in this section a simple new control strategy for utility-connected operation is presented. This minimizes the NDZ by being gently unstable in islanded mode. Unlike [21],[22] however, the instability is not forced by addition of band-pass filters or inverse droop slopes. There is also no modulation of active or active power which might cause flicker violations. The instability arises from the natural phase lags presented by integral control terms, filter time constants, and the generator inertia. Such a simple control scheme allows conventional droop slopes to remain unmodified. Thus, while connected to the utility, the generator will respond sympathetically over a few seconds to provide frequency and voltage support to the wider network, enhancing network stability. This assumes that the generation in the rest of the utility system is at least twice the capacity of the DG, which is usually the case.

\section{A. Active power control loop}

In normal operation, which is connected to the utility (Fig. 1), the active power control system normally allows an arbitrary power setpoint $P_{\text {Set }}$, variable from 0 to 1 pu as desired. A drooped quantity $P_{D}$ is added to $P_{\text {Set }}$, dependent upon the nominal frequency $f_{0}$ (normally 1 ), the measured frequency $f_{M}$, and the droop slope $D_{F}$ (typically $5 \%$ ). A deliberate low-pass filter defined by $\tau_{D P}$ is also applied to the droop signal. An integral control set by $K_{i P}$ closes the feedback loop, such that the prime mover power output approaches $\left(P_{S e t}+P_{D}\right) . M_{F}(s)$ and $M_{P}(s)$ are low-pass filter approximations of the 5-cycle frequency measurement latency [24] and 2-cycle active power measurement latency respectively, and are not dominant in the model. During utility-connected operation, the frequency is essentially fixed by the utility, and the DG unit performs as expected, contributing to frequency support if frequency deviates from $f_{0}$.

If the local power system becomes accidentally islanded, the control system remains the same (LOM has not been detected yet), but the generator electrical output power $P_{G e n}$ is now defined by the load demand $P_{\text {Loads }}$, and frequency is set by the power balance and inertia. The control diagram for this scenario is shown in Fig. 2.

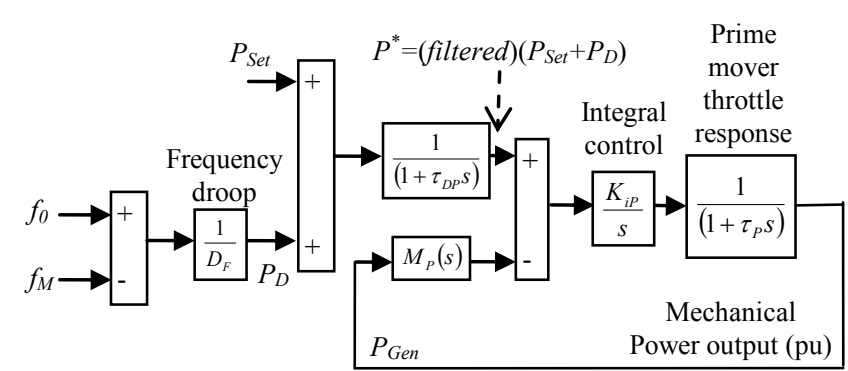

Fig. 1. Active power control system and loop in a utility-connected scenario

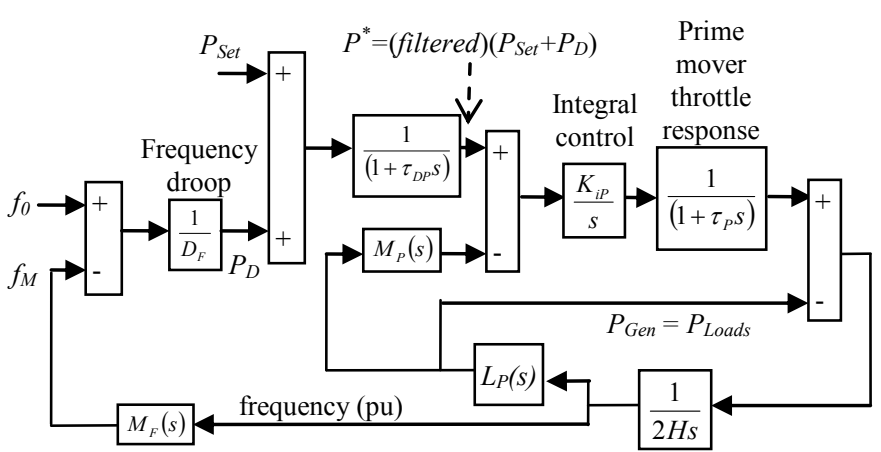

Fig. 2. Active power control loop in an accidentally islanded scenario

In Fig. 2, the system frequency is determined by the perunit inertia $H$ of the DG unit, after accounting for any imbalance between prime mover output power and local load power. The active load power $L_{P}(s)$ (a linearised deviation) can be frequency dependent and include inertia terms. For example, setting $L_{P}(s)$ to $\left(3.3+2 H_{L} s\right)$ forms an approximate linearised model of a load of per-unit inertia $H_{L}$ whose nominal 1pu load also rises with the cube of frequency (such as a fan). Due to the islanded operation, the active power output of the generator is equal to the active load power, and so $P_{\text {Gen }}=P_{\text {Loads }}$.

\section{B. Reactive power control loop}

In utility-connected mode (Fig. 3), the reactive power control system normally allows an arbitrary setpoint $Q_{\text {Set }}$, which can normally be set to 0 for near-unity power factor operation. A drooped quantity $Q_{D}$ is added to $Q_{\text {Set }}$, dependent upon the nominal voltage $V_{0}$ (normally $1 \mathrm{pu}$ ), the measured voltage $V_{M}$, and the droop slope $D_{V}$ (typically $10 \%$ ). A lowpass filter defined by $\tau_{D Q}$ is also applied to the droop. An integral control set by $K_{i Q}$ closes the feedback loop, such that the prime mover power output approaches $\left(Q_{S e t}+Q_{D}\right) . M_{V}(s)$ and $M_{Q}(s)$ are low-pass filter approximations of the 2-cycle measurement latencies of the voltage and reactive power, and are not dominant in the model. During utility-connected operation, the voltage is essentially fixed by the upstream network, and the DG unit performs as expected, contributing to voltage support if voltage deviates from $V_{0}$. 


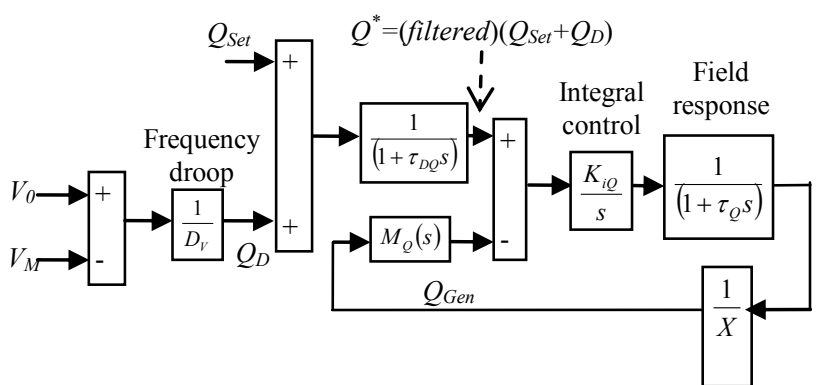

Fig. 3. Reactive power control system and loop in a utility-connected scenario

If the local power system becomes accidentally islanded, the control system remains the same (LOM has not been detected yet), but the voltage is now set by the local DG unit. The control diagram for this scenario is shown in Fig. 4.

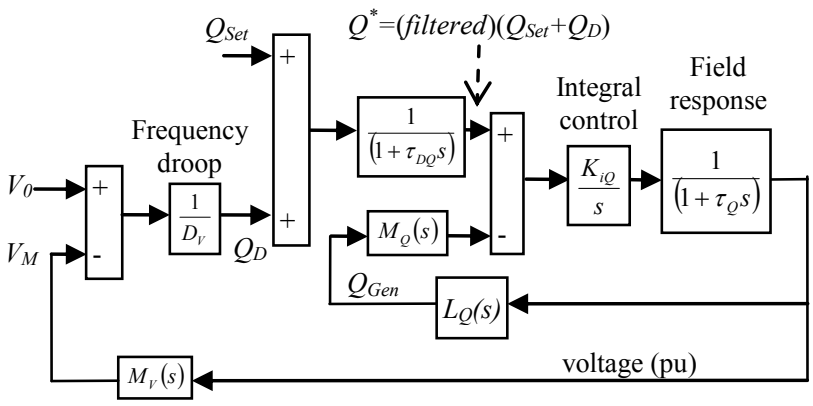

Fig. 4. Reactive power control loop in an accidentally islanded scenario

In Fig. 4, the system voltage is determined by the DG unit. The reactive load power $L_{Q}(s)$ can be voltage dependent. For example, setting $L_{Q}(s)$ to 2.2 approximately models a $1 \mathrm{pu}$ reactive load proportional to $V^{2}$. Due to the islanded operation, the reactive power output of the generator is equal to the reactive load power, and so $Q_{G e n}=Q_{\text {Loads }}$.

\section{Effects not modelled}

The control diagrams of Figs. 1-4 do not account for the cross-coupling between the active and reactive power (frequency and voltage) systems. In practical scenarios, load active power demands can be dependent upon voltage (e.g. heating), and load reactive power demands can be dependent upon frequency (e.g. induction motors). These effects are not explicitly modelled in the analysis which follows. Such effects cause coupling between the P and Q systems, which tend to make both systems unstable in practice if only one is theoretically unstable in isolation.

\section{Qualitative analysis of the control diagrams}

Analysis of the control diagrams resulting from islanded operation (Figs. 2 \& 4) reveals the following dominant characteristics. The active power control loop contains two integral steps, one for the $K_{i P}$ control and one due to system inertia, plus several low-pass filters. Thus, the overall open loop transfer function (OLTF) could have a high gain with $180^{\circ}$ lag at quite modest frequencies. However, both the integral stages are inserted within closed loops, which reduces the gain and lag at the lowest frequencies. Nevertheless, OLTF This is a postprint of a paper published in IEEE Transactions on Smart Grids [http://dx.doi.org/ 10.1109/TSG.2013.2279016] and is subject to IEEE copyright. gain can be significantly greater than unity since $\left(1 / D_{F}\right)$ is typically $1 / 0.05=20$. OLTF gain tends to decrease with increasing frequency, and phase lag tends to increase beyond $180^{\circ}$ as frequency increases. Thus, this system is likely to be unstable over some range of low frequencies.

The reactive power control loop contains only a single integrator due to the $K_{i Q}$ control. Again, this integral stage is also within a closed loop and the effect is mitigated at the lowest frequencies. However, OLTF gain can be significantly greater that unity if $D_{V}$ is small (typically $10 \%$ ). Thus, this system may be marginally unstable at a range of low frequencies, depending upon the relative slopes of decreasing gain and increasing phase lag.

\section{E. Quantitative stability analysis}

Analysis of the OLTFs (from Figs. 2 \& 4) using the parameter settings from Table I results in the bode plots shown in Fig. 5 \& Fig. 6. The tunable controller parameters in Table I were derived from sustained experience and observation of our 2KVA SG when used in grid-connected scenarios. They provide an appropriate dynamic response to network events in that mode of operation. The active power control loop is unstable in isolation (Table II) and is liable to oscillate at a frequency between 0.33 and $0.45 \mathrm{~Hz}$. This instability assists greatly in minimizing the $\mathrm{NDZ}$ of the LOM detection relay. The reactive power control loop is marginally (un)stable (Table II). This means that voltage will not rise or collapse too quickly following islanding, but that the overall coupled PQ system should be unstable.

The instability of the P control system is the most important since it causes the frequency deviations which are the key for most passive LOM detection schemes. However, following an islanding event, any oscillations in the Q control system will also lead to oscillations in voltage that cause load demand changes and, consequently, oscillations/instability within the $\mathrm{P}$ control system.

TABLE I

DEFAULT PARAMETER VALUES USED FOR ANALYSIS

\begin{tabular}{|l|l|l|}
\hline \multicolumn{1}{|c|}{ Parameter } & Value & \multicolumn{1}{c|}{ Description } \\
\hline$\tau_{D P}$ & 0.159 & Time constant for active power droop filter \\
\hline$\tau_{D Q}$ & 0.159 & Time constant for reactive power droop filter \\
\hline$D_{F}$ & 0.05 & $5 \%$ frequency droop \\
\hline$D_{V}$ & 0.1 & $10 \%$ voltage droop \\
\hline$K_{i P}$ & 1 & Active power integral control gain \\
\hline$K_{i Q}$ & 1 & Reactive power integral control gain \\
\hline$\tau_{P}$ & 0.2 & Throttle response time constant \\
\hline$\tau_{Q}$ & 0.2 & Field response time constant \\
\hline$H$ & 1 & Generator per-unit inertia \\
\hline$L_{P}(s)$ & 3.3 & $\begin{array}{l}\text { Stabilising 1pu fan load proportional to } \\
\text { frequency }\end{array}$ \\
\hline$L_{q}(s)$ & 1.32 & $\begin{array}{l}\text { Stabilising 0.6pu (from 1 pu load at } \mathrm{PF}=0.8) \\
\text { reactive load proportional to voltage }\end{array}$ \\
\hline
\end{tabular}




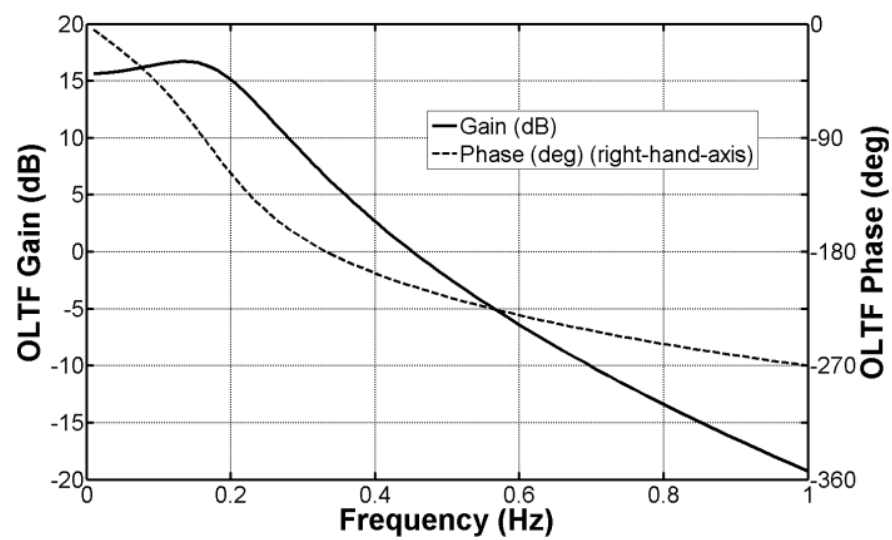

Fig. 5. Active power control, OLTF

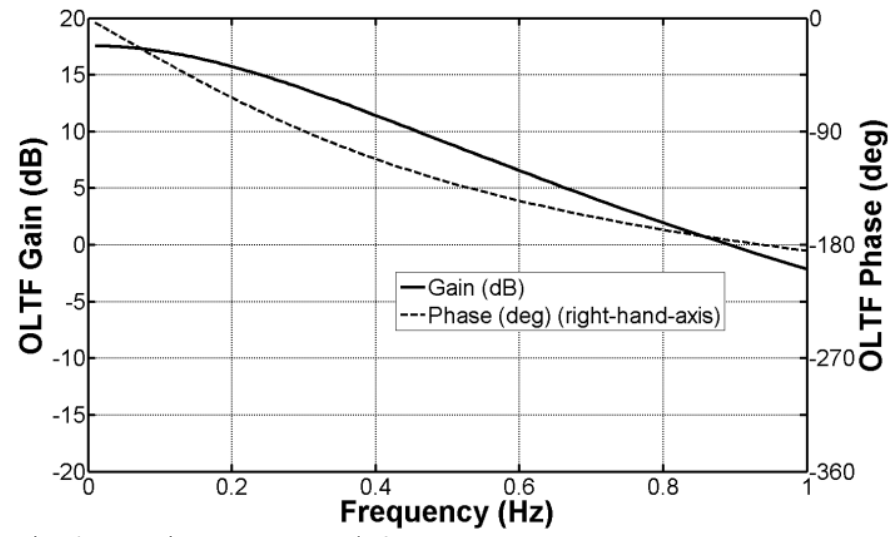

Fig. 6. Reactive power control, OLTF

Further analysis shows that the load inertia can be increased to 2 (giving $L_{P}(s)=4 \mathrm{~s}+3.3$ ) without losing the instability required for decisive operation of the LOM protection. Also, the active power loop is always unstable if $\mathrm{L}(\mathrm{s})$ is 0 or contains only inertia terms in $\mathrm{s}^{1}$ equivalent to inertias of less than 3.6pu, or if the generator inertia dominates. Where concern exists about the instability of either the active of reactive power control loops, a solution is to increase the time constants of the droop filters $\tau_{D P}$ and/or $\tau_{D Q}$. Note that the droop slopes could also be adjusted to achieve instability, but these slopes may be fixed by specific system requirements, whereas the droop filter time constants are independent, freely variable parameters and do not affect the droop slopes. Doubling $\tau_{D P}$ and $\tau_{D Q}$ from 0.159 to 0.318 but leaving all other parameters unchanged changes the gain and phase margins as shown in Table II.

TABLE II

GAIN AND PHASE MARGINS FOR SOME DIFFERENT PARAMETER COMBINATIONS

\begin{tabular}{|c|c|c|c|c|c|c|}
\hline \multicolumn{3}{|c|}{ Scenario } & \multicolumn{2}{c|}{$\begin{array}{c}\text { Active power } \\
\text { control loop }\end{array}$} & \multicolumn{2}{c|}{$\begin{array}{c}\text { Reactive power } \\
\text { control loop }\end{array}$} \\
\hline$\tau_{D P}, \tau_{D Q}$ & $\boldsymbol{D}_{\boldsymbol{V}}$ & $\boldsymbol{L} \boldsymbol{p}(\mathbf{s})$ & $\begin{array}{c}\text { Gain } \\
\text { margin }\end{array}$ & $\begin{array}{c}\text { Phase } \\
\text { margin }\end{array}$ & $\begin{array}{c}\text { Gain } \\
\text { margin }\end{array}$ & $\begin{array}{c}\text { Phase } \\
\text { margin }\end{array}$ \\
\hline 0.159 & 0.1 & 3.3 & $-6.5 \mathrm{~dB}$ & $-27^{\circ}$ & $1.0 \mathrm{~dB}$ & $4^{\circ}$ \\
\hline 0.318 & 0.1 & 3.3 & $-8.3 \mathrm{~dB}$ & $-38^{\circ}$ & $-0.5 \mathrm{~dB}$ & $-2^{\circ}$ \\
\hline 0.159 & 0.4 & 3.3 & $-6.5 \mathrm{~dB}$ & $-27^{\circ}$ & $13 \mathrm{~dB}$ & $73^{\circ}$ \\
\hline 0.159 & 0.1 & 0 & $-85 \mathrm{~dB}$ & $-56^{\circ}$ & $1.0 \mathrm{~dB}$ & $4^{\circ}$ \\
\hline 0.159 & 0.1 & $(2 * 3.6) \mathrm{s}$ & $0 \mathrm{~dB}$ & $0^{\circ}$ & “ & “० \\
\hline 0.159 & 0.1 & $(2 * 2) \mathrm{s}+3.3$ & $0.1 \mathrm{~dB}$ & $0^{\circ}$ & “ & “० \\
\hline
\end{tabular}

\section{F. "Virtual Island" mode}

There is also a variant of the utility-connected active power control mode, called "virtual island" mode, which includes a power-matching function. This mode can be useful, as described above in section II. ,when a change to islanded mode is anticipated, since it will avoid large frequency deviations when the change occurs. It will also be shown (in section IV. V. A. ) that the "virtual island" mode can (counter-intuitively) be used to actively avoid the NDZ.

In "virtual island" mode, the requirement is to set the DG active power output to equal the local site active load demand and minimise power exchange with the rest of the electricity system $[25,26]$. In this case, $P_{\text {Set }}$ is simply set to the measured quantity $M_{P}(s) * P_{\text {Loads }}$, and the droop $D_{F}$ is set to infinity. If the DG becomes islanded, the generator power output already equals the local site load demand and therefore the generator speed should change very little, This avoids the risk of stalling or over-speeding, enabling the DG to ride through the event. The advantage is that the DG can continue to operate after islanding, supplying power to the site load (and the rest of the system once the DG is re-synchronised). The OLTF loop gain becomes close to unity in a positive feedback manner with marginal instability (Fig. 7), and the system frequency will tend to drift away from equilibrium due to any fluctuation in generator or load power. In this configuration the crosscoupling between active and the reactive power control loops means that practically, overall instability with a low resonant frequency results, allowing detection of LOM.

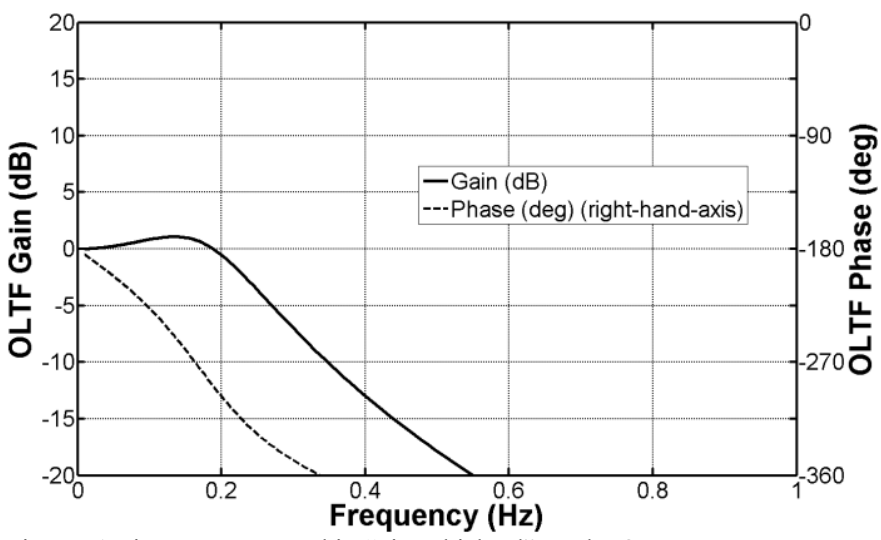

Fig. 7. Active power control in "virtual island" mode, OLTF

\section{G. Practical results}

To verify the performance of the proposed control loops, experiments were conducted using a microgrid containing a $2 \mathrm{kVA}$ synchronous generator (plus prime mover) with $\mathrm{H} \approx 2 \mathrm{~s}$ as the DG unit supplying a controllable load-bank capable of providing resistive and inductive loads over the ranges of zero to $\sim 9.5 \mathrm{~kW}$ and zero to $\sim 7.1 \mathrm{kVAR}$ in steps of $\sim 150 \mathrm{~W}$ and 113VAR (63 steps available independently for active and reactive power). The experimental procedure consisted of synchronizing the local network (DG and loads) to the local utility 3-phase $433 \mathrm{~V}$ distribution network creating scenarios of DG power output (active and reactive) closely matched to the load demand, and then deliberately causing islanding by opening a contactor that normally connects the micro-grid to the utility. Fig. 15 is representative of the setup. The

This is a postprint of a paper published in IEEE Transactions on Smart Grids [http://dx.doi.org/ 10.1109/TSG.2013.2279016] and is subject to IEEE copyright. 
parameters of the DG unit and controls are as shown in Table I, unless stated otherwise.

Initial tests were carried out using $D_{F}$ and $D_{V}$ set to 100 ( $10000 \%$, effectively no droop). It was found possible to create scenarios of sustained non-detection of LOM that lasted over 2 minutes, when the generator and load are powers were very close $(<0.01 \mathrm{pu}$ imbalance), with loss of mains detected successfully only after a load change or a change to the DG setpoints $P_{\text {Set }}$ or $Q_{\text {Set }}$. During such events, frequency and voltage can deviate slowly from their pre-LOM value to new stable values within normal limits.

Next, $D_{F}$ was set to 0.05 (5\% frequency droop) and $D_{V}$ was set to 0.4 (40\% voltage droop). Such a setting of $D_{V}$ means that the reactive power control loop is quite stable in isolation (see Table II). A total of 21 test runs were completed. Due to the instability of the active power control loop, islanding was detected within twelve seconds in all tests. Even the tiniest imbalance (or measurement noise) in the measured active or reactive power is required to start an oscillation in frequency which eventually operates the protection. The average detection time for 20 of the 21 events, for a $0.2 \mathrm{~Hz} / \mathrm{s}$ trigger/trip ROCOF LOM relay, was 3.7 seconds, with a minimum of $<2$ seconds and a maximum of 7.5 seconds. The $21^{\text {st }}$ event produced a trip time of 11.5 seconds, this being due to the generator output power reaching $1 \mathrm{pu}$ limits, thus decreasing the control action A typical well-balanced LOM event with a detection time of 5.5 seconds is shown in Fig. 8 thru Fig. 10.

The LOM event occurs at $t=919.7 \mathrm{~s}$ and is detected at $t=925.2$ seconds (far too long for protection). Fig. 8 clearly shows how the drooped active power target changes in an unstable way subsequent to the LOM event, with resulting oscillations in frequency and ROCOF (Fig. 9). The reactive power control loop also undergoes small oscillations (Fig. 10), although the voltage magnitude deviations are not significant. The actual generator output power $P_{G e n}$ is defined by the load demand $P_{\text {Loads }}$, which only changes slightly due to the voltage variation. Although the frequency deviation enables a clear LOM detection, in this case the detection time is far larger than 2 seconds required by IEEE 1547 and thus this scenario lies within the NDZ of a passive LOM detection relay working on the principle of ROCOF (Rate of change of frequency).

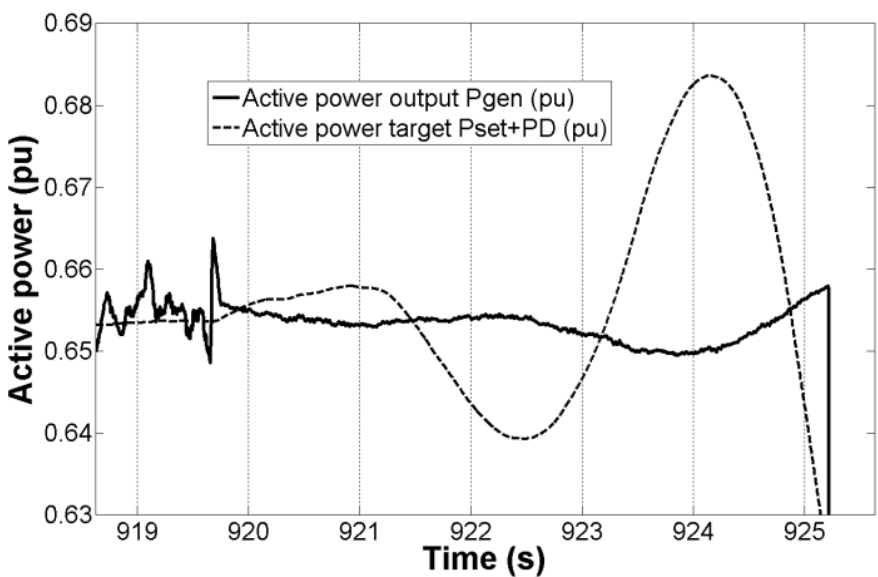

Fig. 8. Unstable power output and target $\left(P_{S e t}+P_{D}\right)$ during a well-matched LOM event

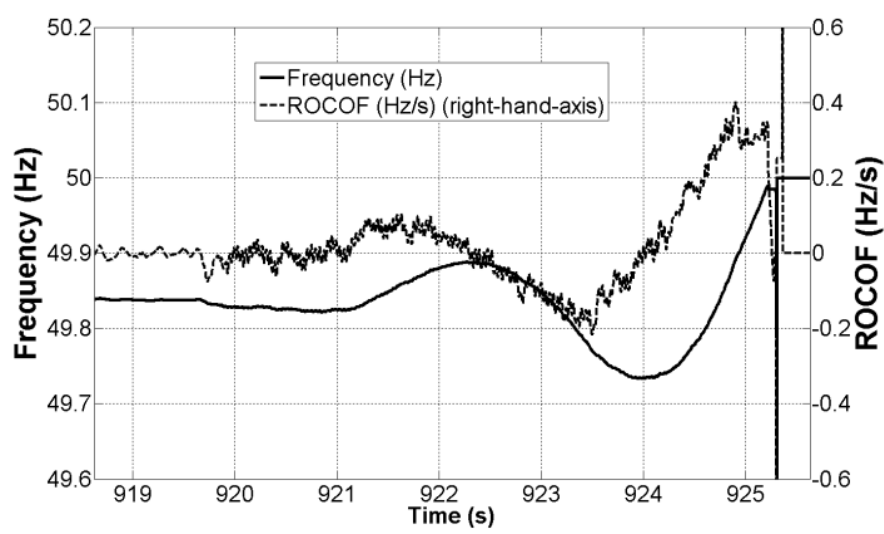

Fig. 9. Frequency and ROCOF deviation during a well-matched LOM event

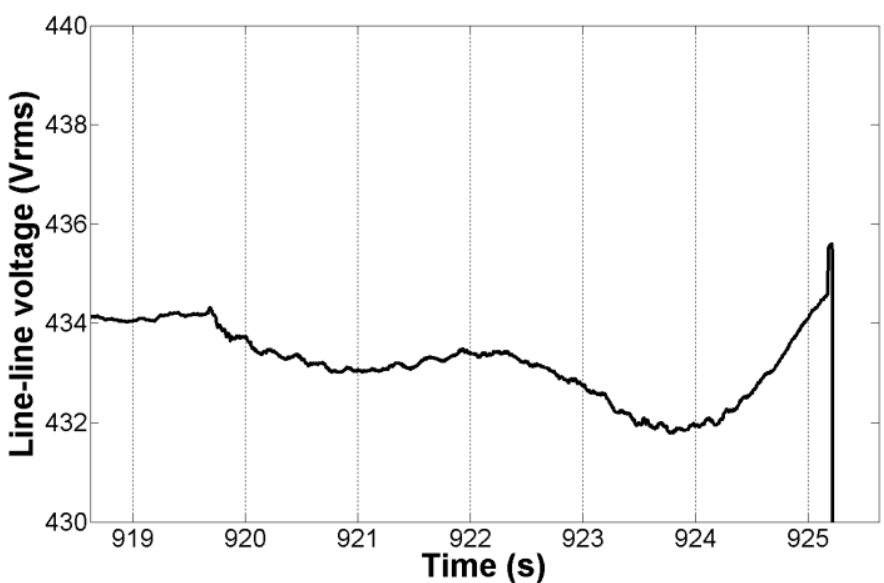

Fig. 10. Voltage during a well-matched LOM event

\section{SimULATIONS USING THE IEEE 1547 TEST ENVIRONMENT}

To further explore the unstable properties of the active ("throttle") and reactive (field) controllers during accidentallyislanded scenarios, a simulation environment has been created in MATLAB ${ }^{\circledR}$ Simulink, which emulates the IEEE 1547 test environment for anti-islanding [27]. This environment includes a tuned RLC load. The power system part of the simulation is shown in Fig. 11, but the entire simulation also includes the active and reactive controllers from Fig. 1 and Fig. 3 using the parameters from Table I.

This is a postprint of a paper published in IEEE Transactions on Smart Grids [http://dx.doi.org/ 10.1109/TSG.2013.2279016] and is subject to IEEE copyright. 


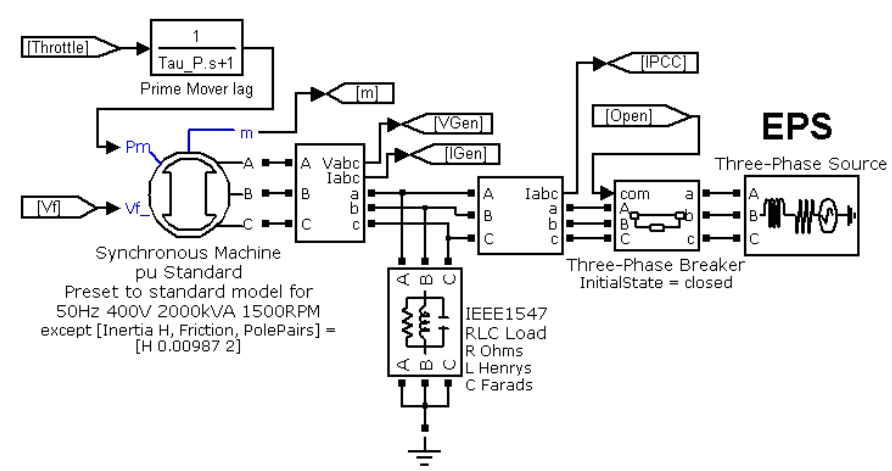

Fig. 11. MATLAB ${ }^{\circledR}$ Simulink SimPowerSystems test environment for IEEE 1547 anti-islanding (LOM) detection testing.

The generator used is the standard model in MATLAB ${ }^{\circledR}$ SimPowerSystems called " $50 \mathrm{~Hz}$ 400V 2000kVA 1500rpm" with a base rating of 2MVA. That machine by default has an inertia $H=0.3072 \mathrm{~s}$, but in the following tests, the inertia is varied from this value up to $H=10 \mathrm{~s}$. Within the IEEE test environment, up to $2 \%$ imbalance in active or reactive power is allowed between the generator output power and the RLC load. This is assessed by measuring the export or import to the EPS (Electric Power System). Unless modulation techniques are used (which are not proposed in this paper), then there is a theoretical risk of non-detection of LOM when the imbalance is exactly zero. However, in practice, using the proposed control loops which are gently unstable, even the tiniest perturbation is enough to cause eventual detection of LOM. The question is whether the detection time can be reduced to 2 seconds as per IEEE 1547, and especially if this can be achieved within the allowed $2 \%$ imbalance - an NDZ of size $0.02 \mathrm{pu}$.

Results from a suite of simulations examining detection times (with a $0.2 \mathrm{~Hz} / \mathrm{s}$ ROCOF threshold) against inertia and reactive power imbalance (export) at the EPS are shown on Fig. 12 and Fig. 13, which show the same data but on different scales. This shows that the strict IEEE 1547 compliance using the proposed control loops would probably only be gained for generators with per-unit inertias of $H=1 \mathrm{~s}$ or less, for which the NDZ is $<0.01 \mathrm{pu}$ wide in reactive power. More detail on the $H=1$ s case is shown in Fig. 14, for both import and export of both reactive and active power at the EPS. This shows that in general the NDZ is smaller for active than for reactive power imbalances. Also, there can be additional effects when the initial power output is $100 \%$, due to saturation of active power controls (clipping at $1.05 \mathrm{pu}$ was modelled) which introduces some non-linearity.

Detection of LOM within 2 seconds can be achieved with larger inertias, but only by increasing the reactive power imbalance to levels above $0.02 \mathrm{pu}$, the largest allowed by the actual IEEE 1547 procedure. However, within a microgrid scenario, if an active management algorithm could keep the power imbalance outside the NDZ at all times (i.e. to avoid the NDZ), this might enable the 2 second detection time to always be met. Such an algorithm is introduced in the next section.

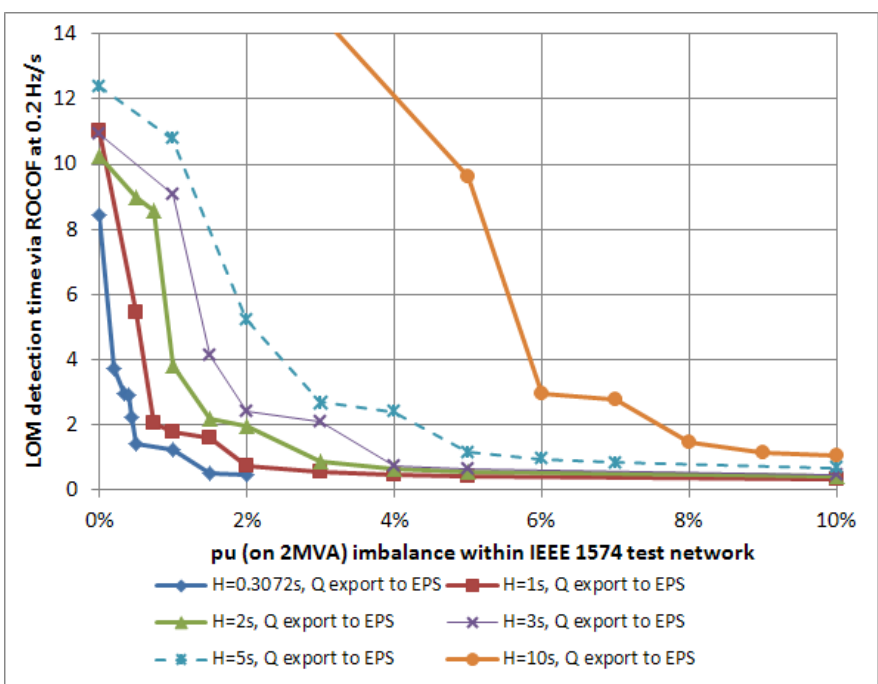

Fig. 12. Detection times (wide view) for DG units with different inertias and different reactive power imbalances. Power output $66 \%$ of rated.

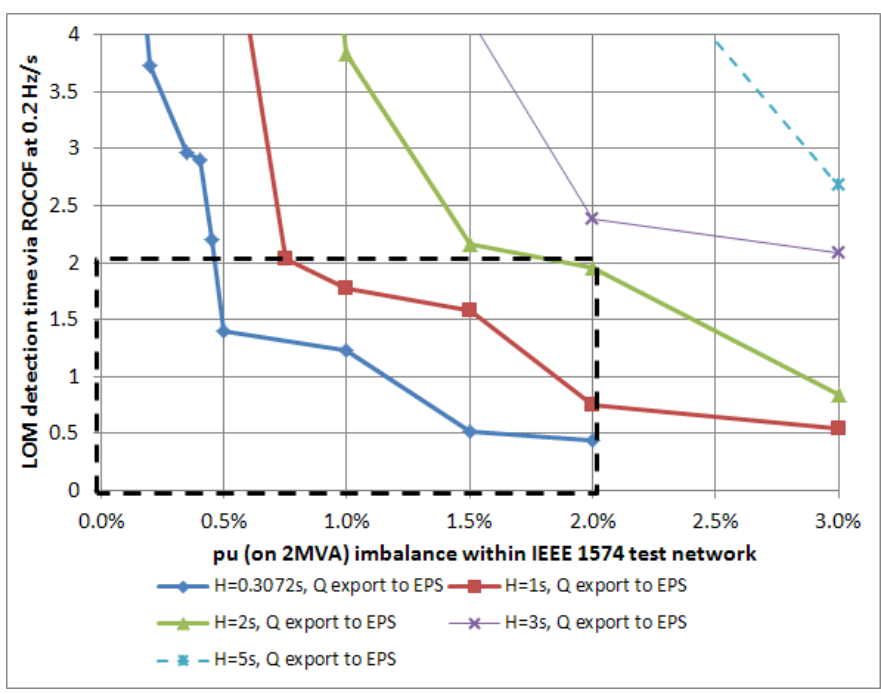

Fig. 13. Detection times (focus on shorter times) for DG units with different inertias and different reactive power imbalances. Power output $66 \%$ of rated.

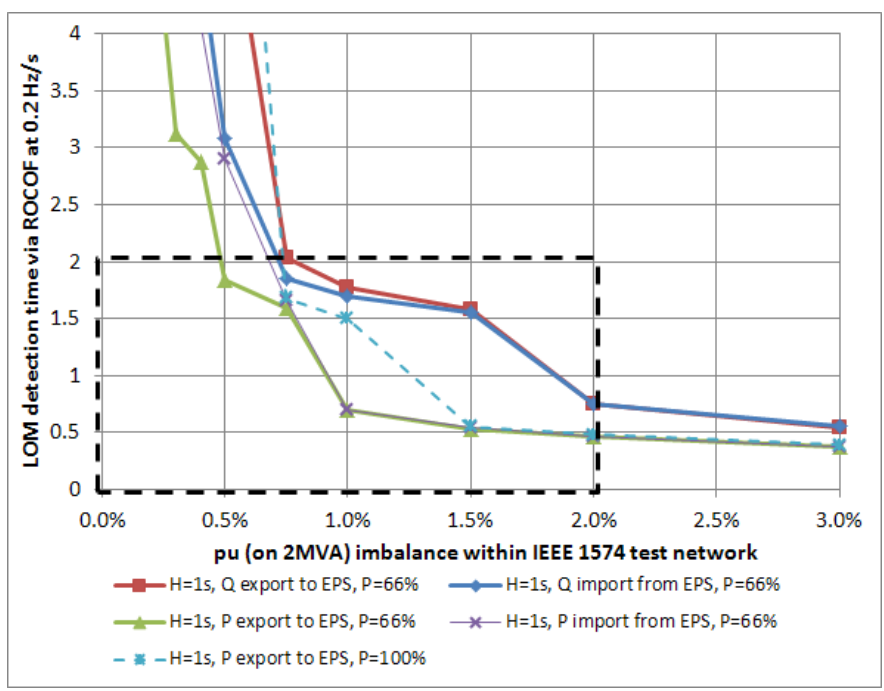

Fig. 14. Detection times for $\mathrm{DG}$ units with $\mathrm{H}=1 \mathrm{~s}$ and both active and reactive power imbalances of different polarities. 


\section{REACTIVE POWER EXCHANGE TO AVOID THE NDZ}

To fully avoid the NDZ of a passive LOM relay, a simple new reactive power management strategy can be used. The context of the strategy is shown in Fig. 15. When a LOM event occurs, any loads which remain within the islanded network are can be termed "trapped". Some of these may be known to a control system, such as the "Local load" on Fig. 15. Other loads may be more distant and may be unknown to any local control system.

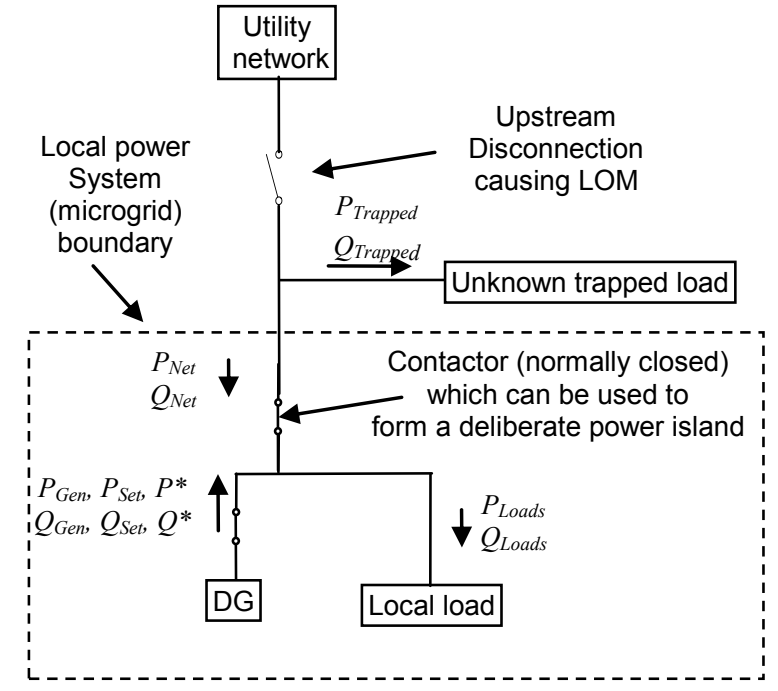

Fig. 15. Context for LOM NDZ avoidance strategy

\section{A. Concept and algorithm}

The concept of the strategy is simple but effective. The preparation stage is to set the values of $P_{t}$ and $Q_{t}$. These define the lower thresholds of active and reactive power exchanges required to avoid the NDZ. In this paper they can be determined from Fig. 12 and Fig. 13, although other sources are (for example) [12]-[14]. Typical values for generators with inertias up to $H=5 \mathrm{~s}$ are $P_{t}=Q_{t}=0.05 \mathrm{pu}$ to guarantee 2 second detection times using the control scheme of section III. , and a passive ROCOF-triggered detection relay set to approximately $0.2 \mathrm{~Hz} / \mathrm{s}$. Widening the ROCOF trigger/trip limit requires raising $P_{t}$ and $Q_{t}$ on an approximately proportional basis, and vice-versa.

Once $P_{t}$ and $Q_{t}$ are set, a cyclic set of algorithmic steps perform the following set of checks and adjustments:

(1) Check the magnitude of the active power exchange $P_{\text {Net }}$. If it is larger than $P_{t}$, no further action is required (go to 4)

(2) Check the magnitude of the reactive power exchange $Q_{N e t}$. If it is larger than $Q_{t}$, then no further action is required (go to 4). To avoid hysteresis problems, this stage actually checks $Q_{\text {Loads }}-Q^{*}$ against $Q_{t}$, which avoids the lagged response of the integral field control and machine response.

(3) If $\left|Q_{\text {Loads }}-Q^{*}\right|<Q_{t}$, then the actual reactive power target $Q^{*}$ used in the control loop is temporarily over-riden, and instead set to $Q_{\text {Loads }} \pm Q_{t}$, the choice of + or - being made such as to minimise the deviation from the usual drooped target value $Q^{*}=Q_{\text {Set }}+Q_{D}$.

(4) Wait for next frame/iteration and then repeat from 1.

Appropriate value and time hysteresis must be added to these decisions in software to avoid cyclic behaviour in real situations. In practice, for example, action (3) can be triggered by $\left|Q_{\text {Net }}\right|$ falling below $Q_{t}$, but once triggered, the action can be continued until $\left|Q_{\text {Net }}\right|$ rises above $2 * Q_{t}$.

In summary, this procedure checks to see if there is an almost exact balance of active power within the local network, and, if so, deliberately creates a slight imbalance in reactive power such that the NDZ is avoided. The reactive power adjustments are small; of the order of $0.05 \mathrm{pu}$. This should cause power-factor (PF) to drop no lower than 0.99 from a starting point of $1 \mathrm{pu}$ active power at $\mathrm{PF}=1.0$. Of course, if active power is smaller than $1 \mathrm{pu}, 0.05 \mathrm{pu}$ of reactive power may equate to a lower power factor due to its proportional contribution.

The adjustment is also made in a steady-state manner as far as possible, with only occasional state changes - the reactive power control is not modulated or dithered. This minimizes the risk of flicker violations due to the operation of the scheme.

The effect of unknown trapped loads (see Fig. 15) should also be considered. The worst case would be if the local generated active power $P_{G e n}$ is not deliberately matched to $P_{\text {Loads }}$ and is in fact accidentally almost matched to $\left(P_{\text {Loads }}+\right.$ $P_{\text {Trapped }}$, and also if a close reactive power match accidentally exists between $Q_{\text {Gen }}$ and $\left(Q_{\text {Loads }}+Q_{\text {Trapped }}\right)$. This is an unlikely but potential scenario. Note that this scenario can be avoided by deliberately matching $P_{G e n}$ (via $P_{S e t}$ ) to $P_{\text {Loads }}$, as via the "Virtual Islanding" function. This means that if $P_{\text {Trapped }}$ is significant, i.e $\operatorname{abs}\left(P_{\text {Trapped }}>P_{\mathrm{t}}\right)$, then $P_{\text {Gen }}$ will never be approximately equal to $\left(P_{\text {Loads }}+P_{\text {Trapped }}\right)$ since $P_{\text {Gen }}=P_{\text {Loads }}$. If $P_{\text {Trapped }}$ is very close to zero, i.e. $\operatorname{abs}\left(P_{\text {Trapped }}\right) \leq P_{t}$, then $P_{\text {Gen }}$ will be very close to $\left(P_{\text {Loads }}+\mathrm{P}_{\text {Trapped }}\right)$ but in this case the algorithmic steps 2) to 3) above will take place. For an accidental close match of reactive power $Q_{\text {Gen }} \approx\left(Q_{\text {Load }}+\right.$ $\left.Q_{\text {Trapped }}\right)$ to then also occur, $\operatorname{abs}\left(Q_{\text {Trapped }}\right)$ would then have to be $\geq Q_{t}$. . This is unlikely if abs $\left(P_{\text {Trapped }}\right) \leq P_{t}$, unless the trapped load (or generator) has an extremely poor power factor, or happens to be a reactive power compensator device.

Thus is can be seen that, (counter-intuitively), use of the "virtual island" function to operate the local power system with a deliberate match of local real power generation to local power demand can be used as a tool to avoid the non-detection zone of loss-of-mains, when the possibility of additional trapped loads exists. This is because the local generation is obliged to supply trapped load (if it exists) following islanding and this disturbs the careful balance of active and reactive power. If there is no trapped active load then the finite reactive power exchange cannot be sustained post-LOM and this instead causes a reactive power disturbance which destabilises the islanded power system.

Further details of this algorithm, including flowcharts, are provided in [13] [28]. 


\section{B. Practical results}

To verify the improvement to LOM detection time, the experimental procedure of section III. was expanded to include the automatic LOM NDZ avoidance algorithm, and the use of the "virtual island" power-matching mode by setting $P_{S e t}$ to the measured value of $P_{\text {Loads }}$. and setting $D_{F}$ to $100(10,000 \%$ frequency droop). $D_{V}$ was set to 0.1 (10\% voltage droop) to ensure that the reactive power control loop is marginally (un)stable when accidentally islanded. $P_{t}$ and $Q_{t}$ were set to $0.05 \mathrm{pu} .16$ Test runs were completed in this configuration, each time with different target values of reactive power exchange. As expected, the LOM NDZ avoidance algorithm disallowed the smallest values of VAR exchange (less than $0.05 \mathrm{pu})$. Fig. 16 shows how the smallest VAR exchanges (which would have led to long LOM detection times) were avoided. This results in a longest detection time of 1.4 seconds, successfully within the 2 seconds allowed by IEEE 1547.

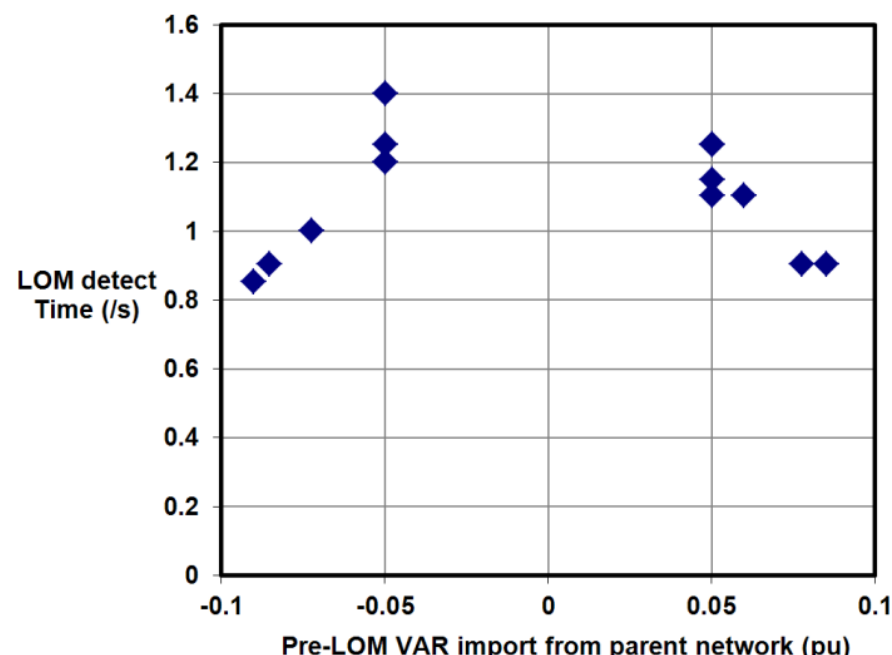

Fig. 16. LOM detection times using proposed controls and LOM avoidance algorithm. $P_{t}=Q_{t}=0.05 \mathrm{pu}$. $0.2 \mathrm{~Hz} / \mathrm{s}$ trigger/trip setting. Active power match

\section{CONCLUSIONS AND FURTHER WORK}

This paper proposes 2 new DG control methods which can be used in combination to guarantee detection of LOM which satisfies the IEEE 1547 requirement for operation within 2 seconds, even with an exact balance of active power between the DG set-point and local load demand.

The first part of the method exploits the natural instability of a utility-connected PQ control scheme with purely integral controls. Only an unstable active power control loop is shown to be required, although an unstable reactive power control loop can also be used to speed up the LOM detection via the coupled dynamics of frequency, voltage, active and reactive power. The proposed control strategies allow sympathetic operation of the DG unit within a utility network, providing frequency and voltage support via conventional droop slopes with appropriate values. Although the detection of LOM is guaranteed, simulation and practical laboratory work shows that in the most well-matched cases, using the drooped control instability alone cannot guarantee the operation of passive
LOM detection within the 2 seconds required by IEEE 1547 . Instead, protection operation took place in times of up to (and exceeding) 12 seconds, while indefinite non-detection was demonstrated by using un-drooped controls.

Therefore, further work reported in section IV. presents a reactive power adjustment strategy to guarantee detection of LOM within 2 seconds. This strategy works by insisting on a microgrid-to-utility reactive power exchange higher than a set threshold, if there is no active power exchange. The strategy may also be used with a "virtual island" function which matches generator output power to local load demand. It is shown that this functional mode does not compromise the NDZ avoidance. In fact, the "virtual island" mode contains its own instability and also accounts for the problems of unknown trapped loads. The strategy requires the measurement of active and reactive power supplied to local loads, which requires instrumentation and communication on a local basis. This may detract from the appeal of the scheme relative to other LOMdetection schemes, if the instrumentation functions are too costly too implement.

The performance of the two schemes combined was examined using a practical microgrid. The longest detection time for a LOM event was 1.4 seconds, even when a deliberate match of active power was made using the "virtual island" function, and reactive power was also as closely matched as the proposed scheme would allow.

To provide more rigorous proof of instability in all scenarios, a full analysis of the coupled active and reactive power control loops could be performed, after allowing for different scenarios of DG and load types. In addition, the practical experimentation could be expanded to include loads with inertia and complex dependence upon frequency [29] (such as fans) and voltage, to verify the expected performance.

\section{REFERENCES}

[1] S. J. Huang and F. S. Pai, "Design and operation of grid-connected photovoltaic system with power-factor control and active islanding detection," IEE Proceedings on Generation Transmission and Distribution, vol. 148, pp. 243-250, May 2001.

[2] M. Ciobotaru, R. Teodorescu, P. Rodriguez, A. Timbus, and F. Blaabjerg, "Online grid impedance estimation for single-phase gridconnected systems using PQ variations," 2007 IEEE Power Electronics Specialists Conference, Vols 1-6, pp. 2306-2312, 2007.

[3] M. Sumner, B. Palethorpe, and D. W. P. Thomas, "Impedance measurement for improved power quality - Part 1: The measurement technique," IEEE Transactions on Power Delivery, vol. 19, pp. 14421448, Jul 2004.

[4] M. Sumner, B. Palethorpe, and D. W. P. Thomas, "Impedance measurement for improved power quality - Part 2: A new technique for stand-alone active shunt filter control," IEEE Transactions on Power Delivery, vol. 19, pp. 1457-1463, Jul 2004.

[5] C. G. Bright, "CoROCOF: comparison of rate of change of frequency protection. A solution to the detection of loss of mains," in Seventh IEE International conference on Developments in Power Systems Protection, Amsterdam, 2001.

[6] X. Ding, P.A.Crossley, and D. J. Morrow, "Protection And Control Of Networks With Distributed Generators Capable Of Operating In Islanded Mode," in Eighth IEE International Conference on Developments in Power System Protection, 2004, pp. 567-570. 
[7] D. Laverty, J. O'Raw, D. J. Morrow, M. Cregan, and R. Best, "Practical Evaluation of Telecoms for Smart Grid Anti-Islanding Protection," in IEEE Innovative Smart Grid Technologies (ISGT) 2011, Manchester, UK, 2011.

[8] A. Dysko, G. M. Burt, and R. Bugdal, "Novel Protection Methods for Active Distribution Networks with High Penetrations of Distributed Generation - Year 2 Report," DTI/CDGSEE/TR/2006-7, 2006. Available: http://www.sedg.ac.uk/DGSEE\%20Protection\%20Project\%20\%20Year\%202\%20Report.pdf, accessed Sept 2012.

[9] W. Freitas, W. S. Xu, C. M. Affonso, and Z. Y. Huang, "Comparative analysis between ROCOF and vector surge relays for distributed generation applications," IEEE Transactions on Power Delivery, vol. 20, pp. 1315-1324, Apr 2005.

[10] J. C. M. Vieira, W. Freitas, Z. Huang, W. Xu, and A. Morelato, "Formulas for predicting the dynamic performance of ROCOF relays for embedded generation applications," IEE Proceedings on Generation Transmission and Distribution, vol. 153, pp. 399-406, Jul 2006.

[11] A. Dysko, C. Booth, O. Anaya-Lara, and G. M. Burt, "Reducing unnecessary disconnection of renewable generation from the power system," IET Renewable Power Generation, vol. 1, pp. 41-48, Mar 2007.

[12] S. Wall, "Detection of islanded behavior and anti-islanding protection of a generator in grid-connected mode," US Patent US6864595, 2005.

[13] A. J. Roscoe, "Measurement, control and protection of microgrids at low frame rates supporting security of supply," PhD thesis, Department of Electronic and Electrical Engineering, University of Strathclyde, Glasgow, 2009, Available: http://strathprints.strath.ac.uk/39631/, accessed June 2013.

[14] H. T. Yip, G. Lloyd, A. Dyśko, G. M. Burt, and R. M. Tumilty, "Islanding Detection Using an Accumulated Phase Angle Drift Measurement," in CIGRE, 2010.

[15] C. An, G. Millar, G. J. Lloyd, A. Dyśko, G. M. Burt, and F. Malone, "Experience With Accumulated Phase Angle Drift Measurement For Islanding Detection," in Developments in Power Systems Protection (DPSP), Birmingham, UK, 2012.

[16] M. Bakhshi and R. G. Noroozian, G.B. , "Passive anti-islanding scheme based on reactive power in the smart grids " in Smart Grids (ICSG), 2nd Iranian Conference on, Tehran, 2012.

[17] IEEE, "IEEE Standard for Interconnecting Distributed Resources with Electric Power Systems," IEEE 1547-2003, 2003.

[18] Z. H. Ye, A. Kolwalkar, Y. Zhang, P. W. Du, and R. Walling, "Evaluation of anti-islanding schemes based on nondetection zone concept," IEEE Transactions on Power Electronics, vol. 19, pp. 11711176, Sep 2004.

[19] J. C. M. Vieira, W. Freitas, W. Xu, and A. Morelato, "Performance of frequency relays for distributed generation protection," IEEE Transactions on Power Delivery, vol. 21, pp. 1120-1127, Jul 2006.

[20] J. C. M. Vieira, W. Freitas, W. S. Xu, and A. Morelato, "Efficient coordination of ROCOF and frequency relays for distributed generation protection by using the application region," IEEE Transactions on Power Delivery, vol. 21, pp. 1878-1884, Oct 2006.

[21] P. Du, J. K. Nelson, and Z. Ye, "Active anti-islanding schemes for synchronous-machine-based distributed generators," IEE ProceedingsGeneration Transmission and Distribution, vol. 152, pp. 597-606, Sep 2005.

[22] Z. Ye and P. Du, "Anti-islanding protection systems for synchronous machine based distributed generators," US Patent US7271571, 2007.

[23] G. Lokov and R. Finstad, "Active anti-islanding system for an electric power plant and his method," European Patent EP1574672, 2012.

[24] A. J. Roscoe, G. M. Burt, and J. R. McDonald, "Frequency and fundamental signal measurement algorithms for distributed control and protection applications," IET Generation, Transmission \& Distribution vol. 3, pp. 485-495, May 2009.

[25] A. J. Roscoe, C. G. Bright, S. J. Galloway, and G. M. Burt, "Increasing Security of Supply by the use of a Local Power Controller during Large System Disturbances," in IEEE PES ISGT Europe 2011, Innovative Smart Grid Technologies, Manchester, UK, 2011.

[26] A. J. Roscoe, R. C. Knight, and D. R. Trainer, "Distributed Generation (A micro-grid control system including an automatic "Virtual Islanding" mode)," International patent application WO2010130583 (A2/A3), 2009.
[27] IEEE, "IEEE Standard Conformance Test Procedures for Equipment Interconnecting Distributed Resources with Electric Power Systems," IEEE 1547.1-2005, 2005.

[28] A. J. Roscoe, "An electrical generator network and a local electrical system (Power flow management to avoid the non-detection of loss of mains (islanding), relays)," International patent applications EP2286499 (A1), WO2009150397 (A1), US2011068631 (A1), 2008.

[29] H. H. Zeineldin and M. M. A. Salama, "Impact of Load Frequency Dependence on the NDZ and Performance of the SFS Islanding Detection Method," IEEE Transactions on Industrial Electronics, vol. 58, pp. 139-146, Jan 2011.

\section{BIOGRAPHIES}

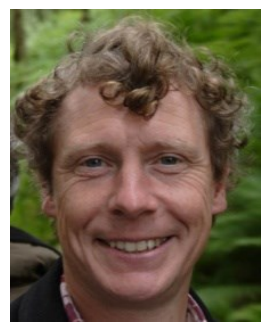

Andrew J. Roscoe received the B.A. and M.A degree in Electrical and Information Sciences Tripos at Pembroke College, Cambridge, England in 1991 \& 1994. Andrew worked for GEC Marconi from 1991 to 1995 , where he was involved in antenna design and calibration, specialising in millimetre wave systems and solid-state phasedarray radars. Andrew worked from 1995 to 2003 with Hewlett Packard and subsequently Agilent Technologies, in the field of microwave communication systems, specialising in the design of test and measurement systems for personal mobile and satellite communications. Andrew was awarded an MSc from the University of Strathclyde in 2004, in the field of "Energy systems and the Environment". In 2009 he was awarded a PhD for developing new power system measurement and microgrid control algorithms. Andrew is currently a lecturer in Smart Grid Integration at the University of Strathclyde, working on micro-grid management, power system measurements, marine power systems, laboratory demonstration with powerhardware-in-the loop capability, connection of offshore renewable generation, and inverter control within microgrids.

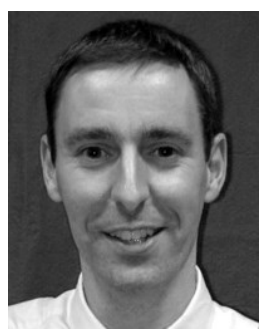

Prof. Graeme M. Burt (M'95) currently holds a chair in Power Systems within the Institute for Energy and Environment at the University of Strathclyde. He received his B.Eng. in Electrical and Electronic Engineering from the University of Strathclyde in 1988. His Ph.D. was awarded in 1992 by the University of Strathclyde following research into fault diagnostic techniques for power networks. $\mathrm{He}$ is currently the Director of the University Technology Centre in Electrical Power Systems sponsored by Rolls-Royce. His current research interests lie in the areas of: protection and control for distributed generation; power system modeling and simulation; and active distribution networks.

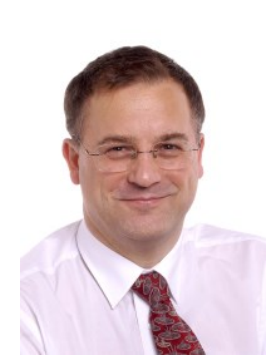

Chris G. Bright received the B.Sc degree in electrical engineering at the University of Southampton, UK, where he also received the M. Phil degree in induction motor control. He worked in the UK electricity supply industry for over 22 years before joining Rolls-Royce where has worked for the past seven years as an Electrical Systems Specialist in their Strategic Research Centre. 